\title{
Exploring Faculty Perceptions of Student Incivility in Social Work: Results from a National Survey
}

\author{
Elizabeth A. Wahler \\ Karen Badger
}

\begin{abstract}
The literature suggests that incivility is a growing problem in college classrooms, but few studies have examined incivility within social work programs. Using a national sample of social work instructors $(n=327)$, this study examined faculty experiences with social work student incivility in both undergraduate and graduate education. Results showed that some behaviors often deemed disrespectful or inattentive do occur in social work classrooms, and they occur more frequently in undergraduate classes than graduate classes. Although rare, hostile behaviors were also reported by faculty. Discussion of these findings includes recommendations for addressing incivility in the context of preparing social work students for professional practice.
\end{abstract}

Keywords: Incivility; social work education; student uncivil behavior

The occurrence of student incivility appears to be on the upswing (Alberts, Hazen, \& Theobald, 2010; Knepp, 2012). Various studies indicate that disrespectful and inappropriate classroom behavior has been increasing across college campuses (Alexander-Snow, 2004; Baker, Comer, \& Martinak, 2008; Boice, 1996). Uncivil student behavior such as arriving late or leaving early, talking inappropriately in class, texting, making confrontational or sarcastic comments to instructors, or using computers for tasks unrelated to class activities can all be distracting to instructors and other students (Ausbrooks, Jones, \& Tijerina, 2011; Boice, 1996; Bjorklund \& Rehling, 2009). Indeed, student incivility, defined as "any speech or action that disrupts the harmony of the teaching-learning environment" (Clark \& Springer, 2007, p. 93), has been documented as a serious problem nationwide in higher education (Alexander-Snow, 2004; Baker et al., 2008; Boice, 1996).

The cultivation of responsible and engaged citizens is among the goals of higher education (Clark \& Springer, 2007). In addition to the traditional emphasis of higher education on preparing students for their careers and fostering their intellectual growth, many educators and administrators also strive to increase students' knowledge of themselves as well as prepare them to be active members in a community (Pascarella \& Terenzini, 2005). This charge suggests that educators influence not only the building of knowledge, but also the development of students' self, particularly in relation to others and their community. Civility has been described as a virtue (Connelly, 2009) and as "...otherregarding in the sense of knowing how to live harmoniously with others and with self" (p. 54). However, the literature documents instances of students (Alberts et al., 2010; Ausbrooks et al., 2011; Bjorklund \& Rehling, 2009; Boice, 1996) as well as faculty (Clark, 2008; Clark \& Springer, 2007) not acting consistently with this virtue. Acts of incivility present educators with the challenge to more intentionally address students' behaviors

Elizabeth A. Wahler, PhD, MSW Program Director/Assistant Professor, School of Social Work, Indiana University, Indianapolis, IN 46202. Karen Badger, PhD, Associate Professor in the College of Social Work, Associate Dean and Assistant Provost in the Division of Undergraduate Education, University of Kentucky, Lexington, KY 40506. 
towards others and, for social work faculty, the opportunity to better align actions with social work values and principles outlined in the National Association of Social Workers Code of Ethics (NASW, 2008).

The social work profession emphasizes core values of service, integrity, social justice, the belief and worth of all people, and the importance of human relationships (NASW, 2008). Acts of incivility in the classroom could be considered as incongruent with these core values and could suggest a student's poor fit with the professional expectations of the social work profession (Ausbrooks et al., 2011). Social work values are basic to social work education as are its competency standards which assert the need for social work graduates to have mastered the forming of a professional identity, practicing ethical behavior, and appreciating and respecting diversity, as well as aligning practice and advocacy efforts to further human rights and justice (Council of Social Work Education [CSWE], 2015b). These central tenets of social work education and the expectation that students be prepared for professional practice mandate that educators influence the shaping of students' professional identities and behaviors. It may be presumed that social work students ascribe to the core social work values and that their behaviors in the classroom and field settings reflect compassion towards others, suggesting that faculty need not be concerned about incivility. However, anecdotal reports of incivility among social work students lead to questions about the actual prevalence of these behaviors. The purpose of this crosssectional study was to explore the type and frequency of uncivil behaviors in undergraduate and graduate classrooms as reported by social work educators.

\section{Overview of Student Incivility in the Classroom}

Boice (1996) conducted an early large-scale empirical study examining incivility in higher education classrooms. He observed instructors and students in large introductory classes (student enrollment of 100 or more) and interviewed samples of both faculty and students. Boice found that incivility took place in most of the classrooms he studied, and faculty with senior rank and teaching experience were not immune. Students and faculty agreed that the most objectionable demonstrations of student incivility were side-talking so loudly that the instructor or students speaking in class could not be heard, reacting to instructors with sarcasm or negative comments, and creating unease in the classroom environment by behaving in a highly emotional or erratic way. Along with identifying problematic student behaviors, Boice observed instructor behaviors/characteristics that were associated with uncivil student behaviors. Boice reported that incivility seemed to be more common in classrooms of instructors whom students perceived as uncaring or unresponsive to their needs. Incivility also perpetuated itself; that is, the more students behaved in an uncivil manner, the more student morale and instructor interest decreased, and the more incivility increased.

Following Boice, others have explored the prevalence of uncivil student behavior in college classrooms and found similar results. Caboni, Hirschy, and Best (2004) investigated student attitudes towards their peers' uncivil behaviors in the classroom and the extent to which the students considered such behaviors to be acceptable. They found that "disrespectful disruptions," behaviors the authors defined as "active behavior in which a student engages that impedes learning by other members of the class" (p. 62) were not 
considered appropriate classroom behaviors. In contrast, "insolent inattention," or disengaged or passive actions that "demonstrate an inability or unwillingness to pay attention to classroom activities" (p. 62) were more likely to be tolerated.

Bjorklund and Rehling (2009) explored the frequency with which students observed incivility in the classroom and asked students to assign severity ratings to each behavior. Behaviors considered more severe included students continuing to talk after being asked not to, coming to class having used drugs or alcohol, letting cell phones ring, and having loud conversations with other students - behaviors that mostly fit the definition of disrespectful disruptions as defined by Caboni and colleagues (2004). However, Bjorklund and Rehling found that the most severely rated behaviors were reported infrequently. Text messaging during class and gathering books and belongings prior to the end of class were the most frequent offenses.

Alberts and colleagues (2010) investigated incidents of student incivility as reported by non-tenured faculty members. They found that the majority of faculty respondents reported incivility in their classrooms. Their findings suggested that larger class size was associated with higher rates of incivility. Smaller formats such as recitation sections, fieldbased experiences, and lab courses were associated with fewer behaviors. The most common type of uncivil student behaviors observed was student inattentiveness. Hostile behavior or language directed towards a faculty member or others were observed to occur infrequently-findings also consistent with previous research.

Although there have been numerous studies examining incivility in general college student samples or specific college majors, we found few using a sample of social work students. Ausbrooks and colleagues (2011) conducted a pilot study examining faculty and student perspectives of incivility in a single social work program. Student study participants rated the acts of incivility as significantly more concerning and occurring more often than their faculty counterparts. However, both groups agreed on which behaviors they considered to be the more serious infractions: "verbal attacking of other students, physically attacking other students, making threats to faculty/students, and making offensive remarks" (p. 263). Faculty and student respondents both reported "eating, talking to other students at inappropriate times, arriving late or leaving early, and text-messaging" (p. 263) as the most frequently observed behaviors. The only other study we found that examined incivility among social work students was a dissertation examining factors affecting perception of incivility among students in a single social work program (Ballan, 2015). Based on the finding that social work students sometimes exhibit uncivil behaviors similar to other college student samples, Ballan suggested this issue be examined on a larger scale with a national sample.

In summary, a review of the literature suggests that student incivility is a common problem on college campuses, suggesting the need to explore this issue within social work programs. Building on two studies of student incivility in single social work programs (Ausbrooks et al., 2011; Ballan, 2015), this study used a national sample of social work faculty to examine the type and prevalence of student incivility in undergraduate and graduate classrooms, compare differences in frequency of incivility between the two levels 
of education, and explore whether experiences of student incivility differed based on faculty demographic characteristics.

\section{Methods}

\section{Study Procedure}

Following approval from the Institutional Review Board, an online survey was distributed via a national social work education organization's listserv comprised of educators, administrators, researchers, and doctoral students (approximate $n=1,400$ ) and the listserv at one of the author's home institution that contained all faculty and staff affiliated with the social work college (approximate $n=100$ ), yielding a general sampling frame of approximately 1,500. Participants were eligible and invited to complete the survey if they had taught either an undergraduate or a graduate social work course within the previous three years. The exact number of eligible individuals receiving the invitation is unknown since the listserv reaches many people who may no longer teach graduate or undergraduate students. Additionally, it is possible that a small number of faculty were on both lists and may have received the invitation twice.

Survey content and procedures followed the guidelines provided by Dillman, Smyth, and Christian (2014). An email informed all listserv recipients of the upcoming survey and invited eligible faculty to consider participating. One week following the initial announcement and description of the study, a second email was sent to invite eligible subscribers to participate and included an embedded link to the on-line survey. The survey could be completed at the respondents' convenience and did not request any identifying data. Within the next three weeks, two reminder emails were sent via the listserv to potential respondents. A return of a completed survey was recognized as consent to participate in the study.

\section{Measures}

The survey consisted of two parts: (a) six demographic items and (b) 29 items listing different behaviors demonstrating classroom incivility compiled from those documented in the extant literature. These items included a range of behaviors often considered inattentive (e.g., sleeping, texting, reading non-class material during class time, using the computer for non-class purposes, etc.), disrespectful (e.g., mocking or making fun of other students, challenging the instructor's authority, arguing about a grade, talking back to the instructor, etc.), hostile (e.g., threatening the instructor, threatening other students, behaving violently in class, etc.), or otherwise inappropriate (e.g. talking over other students, dominating the discussion, not participating in class activities, etc.). Additionally, questions about plagiarism and cheating were included since these have been considered uncivil in previous literature (Bray \& Del Favero, 2004). These issues were considered important in the current study because of their relevance to social work core values (specifically integrity). Eating in class was also included in the survey as a potential uncivil behavior, consistent with other research (Ausbrooks et al., 2011; Bjorklund \& Rehling, 2009; Paik \& Broedel-Zaugg, 2006; Swinney, Elder, \& Seaton, 2010). See Table 2 for a complete list of survey items. For all items, respondents recorded how frequently they had 
observed each type of uncivil student behavior in class using a Likert-type scale of 1 (never experienced) to 5 (usually experienced).

\section{Analytic Plan}

The frequency with which respondents observed each behavior was determined by calculating the mean scores and standard deviation for each behavioral item according to each student group (undergraduates and graduates) using the Likert-type responses. All 29 items were also summed to create an overall index of incivility experienced at the graduate and undergraduate level. Independent samples $t$-tests were calculated to compare means of the individual behaviors and total index scores between those reported in undergraduate and graduate classrooms. Ninety-five percent confidence intervals were computed for the mean difference between behaviors reported at the graduate versus undergraduate level. Cohen's $d$ was computed as a measure of effect size. Demographic variables for faculty members including gender, education level, age categories, and years of teaching experiences were examined for differences in relation to the overall incivility index for each student group using t-tests and one-way analysis of variance (ANOVA).

\section{Results}

\section{Sample Demographics}

Three hundred and twenty-seven $(n=327)$ faculty responded to the survey. This yielded approximately a $22 \%$ response rate when calculating the rate using the total number of subscribers to both listservs. A response rate specific to the eligible faculty from both listservs could not be calculated. In addition, it is unknown what percentage of the total sample was from the social work education listserv versus the university listserv because responses were anonymous. The obtained sample was primarily female $(n=248,76 \%)$ and Caucasian $(n=276,84 \%)$. Comparison to national data on faculty demographics provided by CSWE (2015a) indicated that the demographic characteristics of the current sample were similar to that of the national sample for gender but had a lower percentage of non-White respondents $(36 \%$ of national sample were non-White compared to $15.6 \%$ of the current sample).

\begin{tabular}{|c|c|c|}
\hline \multicolumn{3}{|c|}{ Table 1. Sample Demographics $(n=327)$} \\
\hline \multirow{3}{*}{$\begin{array}{l}\text { Variable } \\
\text { Gender }\end{array}$} & & $\underline{\mathbf{n}(\%) *}$ \\
\hline & Male & $\overline{77(23.7} \%)$ \\
\hline & Female & $248(76.3 \%)$ \\
\hline \multirow[t]{5}{*}{ Race } & Caucasian & $276(84.4 \%)$ \\
\hline & African American & $18(5.5 \%)$ \\
\hline & Asian & $11(3.4 \%)$ \\
\hline & Latino & $8(2.4 \%)$ \\
\hline & Other & $14(4.3 \%)$ \\
\hline \multirow[t]{4}{*}{ Age } & $25-40$ & $57(17.4 \%)$ \\
\hline & $41-50$ & $77(23.5 \%)$ \\
\hline & $51-60$ & $121(37 \%)$ \\
\hline & $61+$ & $72(22 \%)$ \\
\hline \multirow[t]{2}{*}{ Education } & Master's Degree & $103(31.7 \%)$ \\
\hline & Doctoral Degree & $222(68.3 \%)$ \\
\hline \multirow[t]{3}{*}{ Position } & Teaching Assistant & $7(2.1 \%)$ \\
\hline & Adjunct Faculty & $24(7.4 \%)$ \\
\hline & Full-time Faculty & $295(90.5 \%)$ \\
\hline \multirow[t]{3}{*}{ Level } & Undergraduate & $151(46.6 \%)$ \\
\hline & Graduate & $35(10.8 \%)$ \\
\hline & Both & $138(42.6 \%)$ \\
\hline
\end{tabular}
Seventeen percent $(n=57)$ of the respondents were 40 years old or younger with the greatest number of respondents falling in the age category of 51 to 60 years $(n=121,37 \%)$. Most respondents held doctoral degrees 
$(n=222,68 \%)$, and approximately $90 \%(n=295)$ were full-time faculty. About $46 \%$ $(n=151)$ taught only in a social work undergraduate program, approximately $11 \%(n=35)$ only in the graduate social work program, while close to $39 \%(n=128)$ reported that they taught in both programs in the three years prior to completing the survey. Respondents had an average of $14.7(\mathrm{SD}=9.9)$ years of teaching experience, with responses ranging from 1 to 46 years (see Table 1 ).

\section{Prevalence of Incivility}

Faculty respondents were asked to complete survey items related to the student groups they taught; 274 of the participants responded to survey items in relation to undergraduate students, and 157 participants responded to items relative to graduate students (responses total more than the sample of 327 due to some participants teaching at both the undergraduate and graduate levels). The mean scores of types of incivility experienced by faculty teaching BSW and MSW students and $t$ test results are reported in Table 2.

The uncivil behaviors faculty respondents reported as most frequent were generally the same for both student groups, although the order of their prevalence differed. The most frequently reported uncivil behavior at the undergraduate level was tardiness, and this behavior was observed to occur significantly more often with undergraduates $(M=3.48$, $\mathrm{SD}=0.74)$ compared to graduate students $\left(t_{(430)}=7.27, p \leq .001, d=0.70\right)$, although it was also frequently reported by faculty teaching at the graduate level $(\mathrm{M}=2.92, \mathrm{SD}=0.82)$. The most frequently reported uncivil behavior at the graduate level was eating in class $(M=3.51$, $\mathrm{SD}=1.02)$. However, there were no significant differences when compared to the frequency at the undergraduate level $\left(\mathrm{M}=3.41, \mathrm{SD}=1.04, t_{(328)}=-0.97, p=.34, d=0.09\right)$. Other frequently occurring behaviors were talking in class, texting, packing books and papers noisily before the end of class, and dominating the discussion. All of these but dominating the discussion were reported to occur significantly more frequently in undergraduate than graduate classrooms.

Plagiarism was reported to be frequent in both groups, although to a significantly greater extent among undergraduate $(\mathrm{M}=2.68, \mathrm{SD}=0.84)$ than graduate students $(\mathrm{M}=2.33$, $\left.\mathrm{SD}=0.86, t_{(424)}=4.11, p \leq .001, d=0.40\right)$. Cheating on assignments or exams was also reported significantly more often for undergraduate $(\mathrm{M}=2.12, \mathrm{SD}=0.72)$ than graduate students $\left(\mathrm{M}=1.80, \mathrm{SD}=0.75, t_{(428)}=4.37, p \leq .001, d=0.42\right)$.

Hostile and more severe types of incivility were reported at both levels, albeit less frequently than inattentive or disrespectful behaviors. Faculty reported observing general hostility toward other students significantly more often in undergraduate $(\mathrm{M}=1.62$, $\mathrm{SD}=0.66)$ than graduate students $\left(\mathrm{M}=1.44, \mathrm{SD}=0.73, t_{(423)}=2.61, p=.010, d=0.25\right)$. General hostility toward the instructor was also experienced slightly less often for faculty teaching graduate students (undergraduate: $\mathrm{M}=1.72, \mathrm{SD}=0.78$, graduate: $\mathrm{M}=1.55, \mathrm{SD}=0.77$, $\left.t_{(427)}=2.19, p=.030, d=0.21\right)$. There were no significant differences in level of racist comments (undergraduate: $\mathrm{M}=1.53, \mathrm{SD}=0.65$, graduate $\mathrm{M}=1.48, \mathrm{SD}=0.63$ ) or other prejudicial comments in the classroom (undergraduate: $\mathrm{M}=1.90, \mathrm{SD}=0.68$, graduate: $\mathrm{M}=1.83, \mathrm{SD}=0.78$ ). Specific types of hostility, such as threatening others or behaving violently, were experienced rarely. Threatening other students was reported at the same level by faculty who taught undergraduates $(\mathrm{M}=1.16, \mathrm{SD}=0.39)$ and graduate students 
$(\mathrm{M}=1.14$, $\mathrm{SD}=0.42)$. Similar results were found for threatening the instructor (undergraduate: $\mathrm{M}=1.20, \mathrm{SD}=0.45$, graduate: $\mathrm{M}=1.13, \mathrm{SD}=0.41$ ). There were also very few faculty reports of students behaving violently in class for either undergraduate $(\mathrm{M}=1.06, \mathrm{SD}=0.25)$ or graduate $(\mathrm{M}=1.04, \mathrm{SD}=0.19)$ students.

\section{Description of Incivility Experienced}

In addition to the quantitative data gathered in this study, an open-ended item in the survey allowed faculty to write in details of experiences with incivility or mention other types of incivility experienced. Most respondents left this item blank, but some faculty participants described the hostile student behaviors they had experienced. One respondent commented about a student "physically preventing me from leaving my classroom," while others reported "glaring" and "stalking/traumatizing" behaviors in relation to undergraduate students. Respondents who taught graduate students reported students using "profanity towards [the] instructor," as well as "challenging in the form of excessive questioning" and "demanding to meet and talk with [the] professor about personal problems while others are still around after class." One faculty member reported receiving death threats from a student. Additionally, several study participants indicated that they took issue with the inclusion of eating in class on the survey; they communicated that they did not consider it an act of incivility to eat in class and did not think it should be listed as such.

\section{Incivility, Student Education Level, and Faculty Demographics}

Using the summed scores of the 29-item overall incivility index, an independent $t$ - test showed that faculty reported statistically more uncivil behaviors among undergraduates $(\mathrm{M}=62.41, \mathrm{SD}=12.63)$ than graduate students $\left(\mathrm{M}=57.22, \mathrm{SD}=12.73, t_{(375)}=3.81, p \leq .001\right.$, $d=0.39$ ). Faculty demographic variables were then examined relative to student incivility using the overall 29-item incivility index. Independent samples $t$ test analysis showed no statistically significant differences in incivility experienced by gender at either educational level (male $\mathrm{M}=63.29, \mathrm{SD}=13.63$, female $\mathrm{M}=62.05, \mathrm{SD}=12.30, t_{(240)}=0.64, p=.523$ for undergraduate student incivility and male $\mathrm{M}=57.03, \mathrm{SD}=13.13$, female $\mathrm{M}=57.28$, $\mathrm{SD}=12.70, t_{(131)}=-0.10, p=.918$ for graduate incivility) or by faculty education level at the graduate level (master's $\mathrm{M}=55.97, \mathrm{SD}=10.82$, doctoral $\mathrm{M}=57.33, \mathrm{SD}=13.08, t_{(131)}=-0.53$, $p=.598$ ). However, there was a significant difference between student incivility reported by faculty education level for respondents teaching at the undergraduate level. Faculty with a doctoral degree reported more incivility than faculty with a master's degree (master's $\mathrm{M}=59.67, \mathrm{SD}=10.70$, doctoral $\left.\mathrm{M}=63.75, \mathrm{SD}=13.35, t_{(240)}=-2.40, p \leq .05\right)$.

A one-way ANOVA showed no statistically significant differences in experiences of undergraduate or graduate student incivility by faculty age when four categories were used ( $F=0.685, p=.60$ for undergraduate incivility experienced, and $F=0.783, p=.54$ for graduate incivility). Correlations were computed to examine the association between years of teaching experience and incivility with each student group. The number of years of teaching experience was minimally associated with increased faculty experiences of incivility with undergraduate students $(r=.15, p=.02)$ but not with graduate students $(r=.01, p=.94)$. 
Table 2. Mean Frequency of Uncivil Behaviors and Comparisons Between Graduate and Undergraduate Levels $(n=372)$

\begin{tabular}{|c|c|c|c|c|c|c|}
\hline Item & $\begin{array}{c}\text { Undergraduates } \\
\text { M (SD) }\end{array}$ & $\begin{array}{l}\text { Graduates } \\
\text { M (SD) }\end{array}$ & $t$ & $d$ & $\begin{array}{c}\text { Mean } \\
\text { Difference }\end{array}$ & 95\% C.I. \\
\hline Tardiness & $3.48(0.74)$ & $2.92(0.82)$ & $7.27 * * *$ & 0.70 & 0.56 & $.41-.71$ \\
\hline Eating in class & $3.41(1.04)$ & $3.51(1.02)$ & 0.97 & 0.09 & -0.10 & $-.30-.10$ \\
\hline Talking in class & $3.38(0.84)$ & $2.96(0.81)$ & $5.06 * * *$ & 0.49 & 0.42 & $.26-.58$ \\
\hline Texting & $2.96(1.01)$ & $2.53(0.91)$ & $4.40 * * *$ & 0.43 & 0.43 & $.24-.62$ \\
\hline Packing books, etc. noisily before end of class & $2.96(1.04)$ & $2.51(1.02)$ & $4.34 * * *$ & 0.42 & 0.45 & $.25-.65$ \\
\hline Dominating the discussion & $2.76(0.75)$ & $2.69(0.83)$ & 0.89 & 0.09 & 0.07 & $-.08-.22$ \\
\hline Plagiarizing & $2.68(0.84)$ & $2.33(0.86)$ & $4.11 * * *$ & 0.40 & 0.35 & $.18-.52$ \\
\hline Using computer inappropriately & $2.42(0.93)$ & $2.37(0.90)$ & 0.54 & 0.05 & 0.05 & $-.13-.23$ \\
\hline Talking over other students & $2.41(0.79)$ & $2.30(0.82)$ & 1.37 & 0.13 & 0.11 & $-.05-.27$ \\
\hline Reading outside material in class & $2.39(0.83)$ & $2.19(0.87)$ & $2.35 *$ & 0.23 & 0.20 & $.03-.37$ \\
\hline Using cell phone & $2.37(1.03)$ & $2.19(0.92)$ & 1.81 & 0.17 & 0.18 & $-.02-.38$ \\
\hline Sleeping & $2.29(0.81)$ & $1.70(0.75)$ & $7.47 * * *$ & 0.72 & 0.59 & $.43-.75$ \\
\hline Non-verbally making fun of other students & $2.28(0.79)$ & $2.07(0.84)$ & $2.58 * *$ & 0.25 & 0.21 & $.05-.37$ \\
\hline Not participating in activities (no outright refusal) & $2.13(0.91)$ & $1.79(0.75)$ & $3.94 * * *$ & 0.38 & 0.34 & $.17-.51$ \\
\hline Cheating on assignments or exams & $2.12(0.72)$ & $1.80(0.75)$ & $4.37 * * *$ & 0.42 & 0.32 & $.18-.46$ \\
\hline Disrespectfully arguing about a grade & $2.01(0.85)$ & $1.96(0.84)$ & 0.59 & 0.06 & 0.05 & $-.12-.22$ \\
\hline Challenging the instructor's authority & $1.96(0.80)$ & $2.01(0.89)$ & 0.60 & 0.06 & -0.05 & $-.21-.11$ \\
\hline Talking back to the instructor & $1.90(0.81)$ & $1.81(0.83)$ & 1.09 & 0.11 & 0.09 & $-.07-.25$ \\
\hline Inappropriately joking during class for laughs & $1.78(0.75)$ & $1.70(0.73)$ & 1.07 & 0.10 & 0.08 & $-.07-.23$ \\
\hline Behaving with hostility toward the instructor & $1.72(0.78)$ & $1.55(0.77)$ & $2.19 *$ & 0.21 & 0.17 & $.02-.32$ \\
\hline Verbally making fun of other students & $1.68(0.71)$ & $1.56(0.71)$ & 1.69 & 0.16 & 0.12 & $-.02-.26$ \\
\hline Refusing to participate in group activity & $1.66(0.77)$ & $1.50(0.72)$ & $2.12 *$ & 0.21 & 0.16 & $.01-.31$ \\
\hline Behaving with hostility toward other students & $1.62(0.66)$ & $1.44(0.73)$ & $2.61 * *$ & 0.25 & 0.18 & $.04-.32$ \\
\hline Making racist comments in class & $1.53(0.65)$ & $1.48(0.63)$ & 0.77 & 0.07 & 0.05 & $-.08-.18$ \\
\hline Making other prejudiced comments in class & $1.90(0.68)$ & $1.83(0.78)$ & 0.97 & 0.09 & 0.07 & $-.07-.21$ \\
\hline Threatening the instructor & $1.20(0.45)$ & $1.13(0.41)$ & 1.59 & 0.16 & 0.07 & $-.02-.16$ \\
\hline Threatening other students & $1.16(0.39)$ & $1.14(0.42)$ & 0.50 & 0.05 & 0.02 & $-.06-.10$ \\
\hline Throwing small items during class & $1.12(0.35)$ & $1.11(0.33)$ & 0.29 & 0.03 & 0.01 & $-.06-.08$ \\
\hline Behaving violently in class & $1.06(0.25)$ & $1.04(0.19)$ & 0.87 & 0.08 & 0.02 & $-.02-.06$ \\
\hline Total Index Score & $62.41(12.63)$ & $57.22(12.73)$ & $3.81 * * *$ & 0.39 & 5.19 & 2.51-7.87 \\
\hline
\end{tabular}

$* p \leq .05, * * p \leq .01, * * * p \leq .001$ 


\section{Discussion}

Social work educators who participated in this study reported observing behaviors of incivility during interactions with both their undergraduate and graduate students. Although found in both student groups, incivility was reported with significantly greater frequency in undergraduate courses. The student demographics in this study are not known, but traditional undergraduate students tend to be younger than social work graduate students. Undergraduates might also have less socialization into the culture of higher education and less familiarity with expectations of the social work profession. In addition, we should note that all of the undergraduate students who exhibited uncivil behaviors may not be BSW majors. In some schools, BSW students may not declare a major until their junior year. Likewise, non-social work majors may take some undergraduate social work courses.

Overall, findings regarding types of incivility observed and experienced were consistent with those reported in similar studies. The most frequently reported behaviors of incivility were those that could be categorized as disrespectful or inattentive, such as tardiness, texting, or talking in class. More severe behaviors, such as behaving threateningly or violently, were experienced by respondents to a far lesser extent. The results of the current study are consistent with previous research literature using both social work (Ausbrooks et al., 2011; Ballan, 2015) and non-social work (Alberts et al., 2010) samples. Faculty respondents in the study by Alberts and colleagues reported eating, talking to other students inappropriately, being tardy or leaving early, and texting in class as the behaviors they most frequently experienced in undergraduate and graduate students combined. In addition to faculty reports, student respondents in other studies show that they also noticed these uncivil behaviors in class. The behaviors reported as most frequently observed by faculty in this current study were also among those most frequently observed by students reporting about incivility among their peers in a previous study (Bjorklund \& Rehling, 2009).

The lack of consensus in the literature about what behaviors constitute incivility (Boice, 1996) is also evident in this study. While behaviors that are hostile (e.g., behaving violently in class, threatening other students or the instructor, making hostile comments, etc.) are more consistently accepted as incivility, other behaviors deemed uncivil by some are not considered as such by others. For example, in the current project, eating in class was included as an uncivil behavior as it has been in other studies (Ausbrooks et al., 2011; Bjorklund \& Rehling, 2009; Paik \& Broedel-Zaugg, 2006; Swinney et al., 2010), and was the item most frequently experienced by respondents. However, several participants reported in the open-ended survey question that they took issue with eating being included in a survey on incivility and did not feel it was inappropriate to eat in class. Their reactions to this item were consistent with findings in a previous study in which only a small percentage of the faculty respondents perceived this behavior as uncivil (Swinney et al., 2010).

With future research in mind, this study highlights the influence that individual characteristics (e.g., subjectivity, preferences, and perceptions) can have when studying classroom incivility. It also demonstrates the importance of measuring the degree to which 
a behavior is uncivil. For example, a student who is quietly eating a small snack during class yet still engaged could be considered as exhibiting acceptable behavior, while a student who brings in a full meal in noisy containers and is pre-occupied with their meal rather than attending to the class could be considered as behaving in an uncivil manner. Where a specific behavior is placed on such a continuum can determine how intrusive it is to the learning environment. However, instructors may see some behaviors as less serious and more tolerable than the students who also observe the actions (Ausbrooks et al., 2011). Faculty ought to take student perspective and experience into account when making decisions regarding the acceptability of these behaviors. In addition, behaviors that are, at first glance, considered tolerable may become quite disruptive if their occurrence is high. For example, one student arriving a few minutes late to class may create no or minimal disruption, but many students arriving late and at different times during class could negatively impact the learning experience for both the instructor and the students.

It is worth noting that some respondents sent emails to the authors in addition to their responses to the survey instrument to share that, in general, they struggled with labeling behavior as incivility. These respondents stated that social work students should be encouraged to question authority, argue about their grades, and talk back to the instructor since social work educators should also be teaching about the need to act uncivilly to fight against social injustice. These comments highlight a conflict regarding civility likely not present in literature regarding professions other than social work and one that should be the focus of future research on incivility in our field. Social work educators are expected to assist students in developing advocacy skills and to embrace social work's mission of addressing social injustice (CSWE, 2015b; NASW, 2008), but also need to strike a balance of doing so by still encouraging students to exhibit proper classroom behavior without being oppressive. Social work educators most likely vary regarding the level of authoritychallenging behavior they accept from students as being appropriate; thus, it is even more important that each institution or faculty group delineate specific definitions of inappropriate and intolerable behavior from students to aid in identifying and addressing uncivil behavior within the implicit curriculum.

In this study, faculty members' gender and level of education were not statistically significantly related to the frequency of overall uncivil behaviors reported for either undergraduate or graduate students. Similar to this finding, Alberts et al. (2010) did not find statistically significant differences in relation to gender and reports of disrespectful or inattentive uncivil behaviors in their sample. However, their results did show that female faculty reported experiencing more incidents of hostility from students than their male counterparts. Additionally, a mild positive correlation was found in the current study between years of experience and incivility experienced with undergraduate students, but not with graduate students. These findings contrast with those of Boice (1996), who found that years of teaching experience were not correlated with experiences of incivility, but found instead that faculty characteristics (such as standoffishness) or behaviors (such as racing through a lecture) were associated with students' uncivil behaviors. These faculty characteristics and behaviors should be measured in future research on student incivility in social work. 


\section{Developing Professional Behaviors in the Classroom}

Student incivility runs counter to the high professional standards of social work. The social work core competency, demonstrate ethical and professional behavior (CSWE, 2015b), requires students to master practice behaviors (or student learning outcomes) such as self- reflection and subsequent behavioral correction, as well as behaving, appearing, and communicating as a professional in accordance with social work roles and the profession's standards and values. Although such an emphasis may create the expectation that social work educators do not experience incivility, the findings of this study as well as those of Ausbrooks et al. (2011) and Ballan (2015) indicate otherwise. Thus, through using the purpose, competencies, and values of social work as a guide, social work educators have the opportunity to model appropriate professional behavior in class and address incivility in a way that reinforces social work professionalism and the development of congruent attitudes and behaviors. The literature presents strategies educators can implement to manage these student improprieties (Baker et al., 2008; Bjorklund \& Rehling, 2009, McNaughton-Cassill, 2013; Nordstrom, Bartels, \& Bucy, 2009; Royse, 2001; Suplee, Lachman, Siebert \& Anselmi, 2008), some of which may resonate with social work educators. For example, it has been suggested that the presence of learning goals has been correlated with a decrease in inappropriate behavior (Nordstrom et al., 2009), findings which support reviewing the CSWE (2015b) core educational competencies with students at the start of a course and reinforcing them throughout the curriculum.

Students may be more likely to meet behavioral standards in class if they understand how the standards apply to their future professional practice. Rather than only emphasizing rules and requiring civil behavior for the purposes of class, the instructor can map their importance for shaping of students' future behaviors and appearance as social workers, explaining how civility fits with professional values and norms as well as with its role in establishing professional credibility. If students demonstrate inappropriate classroom behavior, instructors can define and reframe for students why it is inappropriate in the real world and how this is relevant for their future careers (Fink, 2003). For instance, if a group of students is observed mocking another student in class, the instructor could discuss with them the social worker's responsibility to serve those who are marginalized by society. These students could be asked to envision themselves working with a client who is similar to the student they are mocking and be reminded that the classroom is where they can begin practicing those behaviors they will apply in the field. Another example concerns plagiarism, which corresponds with the social work value of integrity. Investigations of an alleged act of plagiarism can also include exploring the context within which the student made the decision to use another's material without proper credit. Although specific reasons for plagiarism should be the focus of future research, some students might describe feeling overwhelmed, stressed, unsure of how to do an assignment, or being out of time as explanations for plagiarism. In circumstances such as these, the possible ramifications of being in a practice setting and choosing to resolve problems by taking short cuts or misrepresenting work, etcetera, can then be discussed. Additional problem-solving routes can be explored to connect the classroom behavior with professional expectations. If instructors introduce the classroom atmosphere as one similar to that established in social work practice - where all students (and the instructor) are expected to be treated and treat 
others with fairness and compassion - the stage is then set for making a connection between in-class behaviors and those essential for success in future practice settings.

Incivility has also been described as consisting of an "interactional effect between students and faculty" (Bray \& Del Favero, 2004, p. 10) and as occurring within this relational context and/or that of the classroom milieu. Bray and Del Favero (2004) discuss student incivility from the perspective of social control theory - which describes "deviance as a lack of adequate socialization into the culture" (p. 11). In social work education, the culture into which students are socialized is the classroom, but it also extends beyond and includes the norms and behaviors expected within field settings and the wider social work profession. Given this, incidents of student incivility present social work educators with the opportunity to reinforce social work values and to emphasize the development of professional attitudes and behaviors. In social work education, students are socialized into the profession through field work with community-based social workers, providing students with opportunities to integrate the knowledge, values, and skills they have learned in the classroom. Consistent with the assumptions of social learning theory (Abbey, Willett, Selby-Penczak, \& McKnight, 2010), students are also able to learn new behaviors through observation and application. Classroom-based social work educators are also in the position to model professional behaviors and expectations for students. Classroom observations and interactions (with peers and instructors alike) can impart professional norms and values and create learning opportunities for students (Abbey et al., 2010). For example, if professional social workers are expected to be prepared, reliable, and respectful of others, this could be modeled by the classroom instructor (e.g., being on time for class, preparing the class session, providing an organizational structure, and actively listening to students) and, in turn, be expected of the students (e.g., being on time for class, having completed the required readings, using electronic devices appropriately during class, completing homework on time, and attending to class discussion).

Also of note, uncivil student behavior could signal underlying social or psychological problems (McNaughton-Cassill, 2013) that need to be addressed through referrals for services. Although this could be challenging for all educators, perhaps it could be especially difficult for faculty who might also be social work practitioners in the field. Social work educators should be careful to establish appropriate boundaries, work within their ascribed roles, and not provide social work services to students in their classes. Besides dual relationships being prohibited by the NASW Code of Ethics (2008), counseling students can confuse classroom roles, reduce instructors' objectivity in class, and increase chances students will feel personally rejected by instructors' feedback or by receiving a lower grade than desired (Royse, 2001). All of these factors have the potential to feed incivility rather than improve behavior. Depending on the severity of the problem, the student's willingness to address it, and the student's ability to fulfill requirements of the educational competencies, it could also be appropriate at times to discuss the fit of the student with social work and coach them toward other career options.

\section{Limitations and Future Directions}

Although this study contributes to knowledge about incivility among social work students, there are several limitations that must be considered. Self-reported data were used 
in this study which are vulnerable to selective recall and potential bias. The study sample was not highly diverse in regards to ethnicity, and the diversity of the sample in terms of geographic or academic location is unknown. This study did not include environmental context variables such as the type of school (e.g., small or large institutions, private or public institutions) or the size of the classes or status of students (freshmen, sophomore, senior) taught by faculty respondents. Additionally, student variables such as age, declared major, and familiarity with the NASW/CSWE core principles and competencies could also influence uncivil behavior and were not included in this or other studies of social work student incivility. These variables could potentially influence the degree to which faculty experience student incivility and should be considered in future research on this topic. The actual response rate of the sample could not be calculated as the number of listserv subscribers who fit the eligibility criteria was not known to the researchers.

Despite the limitations, this study extends the exploratory work completed by Ausbrooks et al. (2011) and Ballan (2015), and the results continue to suggest that additional investigation in this area is needed to further examine incivility in social work education. Specifically, to better understand its occurrence, the contributions of instructor, student, and university attributes to incivility should be studied. Studies might examine the prevalence with which faculty incivility, as well as student incivility, is present in social work education. Exploring social work students' perceptions of student and faculty incivility is needed to better understand the students' experiences in the classroom and what circumstances detract from learning. With the growth of online education, future research should examine prevalence of incivility in online settings and interactions. Future research should also examine the efficacy of preventive methods and interventions for addressing incivility in social work classrooms so that social work educators can intervene with evidence-supported methods.

In closing, social work educators have an important role in socializing students into the social work profession, its values, and expectations. Those who encounter acts of student incivility in their classrooms are presented with teachable moments. Addressing uncivil behavior in the context of social work practice and linking civility with expectations that students will experience as future social workers can contribute to their development as social work professionals and foster the shaping of engaged citizens.

\section{References}

Abbey, L., Willett, R., Selby-Penczak, R., \& McKnight, R. (2010). Social learning: Medical student perceptions of geriatric house calls. Gerontology \& Geriatrics Education, 31(2), 149-162. doi:http://dx.doi.org/10.1080/02701961003795771

Alberts, H. C., Hazen, H. D., \& Theobald, R. B. (2010). Classroom incivilities: The challenge of interactions between college students and instructors in the U.S. Journal of Geography in Higher Education, 34(3), 439-462. doi:http://dx.doi.org/10.1080/03098260903502679

Alexander-Snow, M. (2004). Dynamics of gender, ethnicity, and race in understanding classroom incivility. New Directions for Teaching and Learning, 99, 21-31. doi:http://dx.doi.org/10.1002/tl.155 
Ausbrooks, A. R., Jones, S. H., \& Tijerina, M. S. (2011). Now you see it, now you don't: Faculty and student perceptions of classroom incivility in a social work program. Advances in Social Work, 12(2), 255-275.

Baker, S. D., Comer, D. R., \& Martinak, M. L. (2008). All I'm askin' is for a little respect: How can we promote civility in our classrooms? Organizational Management Journal, 5, 65-80. doi:http://dx.doi.org/10.1057/omj.2008.8

Ballan, A. O. (2015). The selfie generation: Students' perceptions of classroom incivility in social work education (Doctoral dissertation). Retrieved from http://media.proquest.com/media/pq/classic/doc/3747880191/fmt/ai/rep/NPDF?_s=v \%2FF9cBuj2D\%2F6rwwZAcLWnczClxA\%3D

Bjorklund, W. L., \& Rehling, D. L. (2009). Student perceptions of classroom incivility. College Teaching, 58, 15-18. doi:http://dx.doi.org/10.1080/87567550903252801

Boice, B. (1996). Classroom incivilities. Research in Higher Education, 37(4), 453-486. doi:http://dx.doi.org/10.1007/BF01730110

Bray, N. J., \& Del Favero, M. (2004). Sociological explanations for faculty and student classroom incivilities. New Directions for Teaching and Learning, 99, 9-19. doi:http://dx.doi.org/10.1002/tl.154

Caboni, T. C., Hirschy, A. S., \& Best, J. R. (2004). Student norms of classroom decorum. New Directions for Teaching and Learning, 99, 59-66. doi:http://dx.doi.org/10.1002/tl.159

Clark, C. M. (2008). Student voices on faculty incivility in nursing education: A conceptual model. Nursing Education Perspectives, 25(5), 284-289.

Clark, C. M., \& Springer, P. J. (2007). Thoughts on incivility: Student and faculty perceptions of uncivil behavior in nursing education. Nursing Education Perspectives, 28(2), 93-97.

Connelly, R. J. (2009). Introducing a culture of civility in first-year college classes. Journal of General Education, 58(1), 47-64. doi:http://dx.doi.org/10.1353/jge.0.0029

Council on Social Work Education [CSWE]. (2015a). Annual statistics on social work education in the United States. Retrieved from http://www.cswe.org/File.aspx?id=94118

CSWE. (2015b). Educational policy and accreditation standards (EPAS). Retrieved from http://www.cswe.org/File.aspx?id=81660

Dillman, D. A., Smyth, J. D., \& Christian, L. M. (2014). Internet, phone, mail, and mixed-mode surveys: The tailored design method. Hoboken, NJ: John Wiley.

Fink, L. D. (2003). Creating significant learning experiences. San Francisco, CA: JosseyBass.

Knepp, K. A. F. (2012). Understanding student and faculty incivility in higher education. Journal of Effective Teaching, 12(1), 32-45. 
McNaughton-Cassill, M. E. (2013). Is it incivility or mental illness? Understanding and coping with disruptive student behavior in the college classroom. Journal of Effective Teaching, 13(2), 94-108.

National Association of Social Workers. (2008). Code of ethics. Retrieved from http://www.socialworkers.org.pubs/code/code.asp

Nordstrom, C. R., Bartels, L. K., \& Bucy, L. (2009). Predicting and curbing classroom incivility in higher education. College Student Journal, 43(1), 74-85.

Paik, C., \& Broedel-Zaugg, K. (2006). Pharmacy students' opinions on civility and preferences regarding professors. American Journal of Pharmaceutical Education, 70(4), 1-9. doi:http://dx.doi.org/10.5688/aj700488

Pascarella, E. T., \& Terenzini, P. T. (2005). How college affects students, volume 2: A third decade of research. San Francisco, CA: Jossey-Bass.

Royse, D. (2001). Teaching tips for college and university instructors. Needham Heights, MA: Allyn \& Bacon.

Swinney, L. S., Elder, B. R., \& Seaton, L. P. (2010). Incivility in the accounting classroom. American Journal of Business Education, 5, 1-16. doi:http://dx.doi.org/10.19030/ajbe.v3i5.422

Suplee, P. D., Lachman, V. D., Siebert, B., \& Anselmi, K. K. (2008). Managing nursing student incivility in the classroom, clinical setting, and on-line. Journal of Nursing Law, 12(2), 68-77. doi:http://dx.doi.org/10.1891/1073-7472.12.2.68

\section{Author note}

Address correspondence to: Elizabeth A. Wahler, Assistant Professor in the Indiana University School of Social Work, 902 W. New York Street, ES 4158, Indianapolis, IN 46202 or bwahler@iupui.edu 